\title{
A Taoist Perspective of Expressive Arts Therapy - Introduction to Hong Kong Special Edition Hong Kong 2020
}

\author{
從道家思想初探表達藝術治療 - 香港2020年特刊簡介 \\ Lai Ka Kit 黎家傑 \\ Kunst Expressive Arts Therapy Academy, Hong Kong, China
}

\begin{abstract}
Drawing on the articles in the Hong Kong special edition of the journal Creative Arts in Education and Therapy (CAET), Eastern and Western Perspective, the author raises questions as to the way (tao) and a way of (re)imagining the local challenges. These questions serve as the responses of the author in the spirit of Zhuangzi's wandering $(y u)$ among these articles and have led him to consider how he could (re)imagine addressing these questions from the perspective of the Chinese and Asian worldviews.
\end{abstract}

Keywords: Hong Kong, Expressive Arts therapy, Taoism, Zhuangzi, East-West

\section{摘要}

對應於 CAET期刊香港特刊收錄的多篇文章，本文作者嘗試提出一些相關的問題，並嘗試 從「道」提出一個方向，作為一個方法，從新想像這一年來發生在香港本地的挑戰。透過 莊子哲學的精神，尤其關於「遊」的詮釋與想像，成為作者對於這些文章的回應在這思 考框架底下，帶領作者去考量，如何能夠透過中國/亞洲的世界觀去從新想像如何回應這 些文章中談及的本土表達藝術治療現象.

關鍵字 : 香港, 表達藝術治療, 道家哲學, 莊子，東西方文化的世界觀

\section{Taoist philosophy and Expressive Arts therapy}

Being born in Hong Kong, I have a special interest in constructing a dialogue between Expressive Arts therapy and Taoist philosophy, especially as regards Zhuangzi (莊子). Master Zhuang Zhou, known as Zhuangzi, is a pivotal figure in Taoist philosophy and the Zhuangzi is a compilation of the writings of Master Zhuang Zhou and other philosophers from the Classical Period in China during the Warring State Period (481403 BCE).

When compared with Laozi (the founder of philosophical Taoism and author of the Tao Te Ching), who is fluid on discourse about propositions, Zhuangzi is a master at asking questions, including rhetorical ones and ones concerning real doubts (Zhou, Cheng \& Lui, 2019). In the spirit of Zhuangzi I ask questions as a way of introducing the articles in this issue of the journal. I perceive the act of asking question as the way (tao) and a way of (re)imagining challenges or problems. The questions I ask are inspired by the authors of this special issue and have led me to consider how we could (re)imagine addressing these questions from the perspective of Chinese and Asian worldviews. 
By using the arts as a way of asking questions, we are permitted to wonder, and to wander away from our already entrenched preconceptions. In light of Taoist philosophy I offer a "reading strategy" for the articles. We have read them alongside Laozi, with his words as a guide:

\section{「反者道之動; 弱者道之用 天下萬物生於有，有生於無 (道德經第40章)}

The movement of the Tao proceeds by opposites; and weakness is the means the Tao utilizes.

All creation is born from the being, while being is born from the non-being.

(Tao Te Ching, chapter 40)

These four lines contain multiple ideas relating to Taoist philosophy. Let us look at each line more carefully.

"The movement of the Tao proceeds by opposites;"

Laozi urged us to be open to and embody the flow of the "positive" and "negative" movements. "Positive" and "negative" in this context are not used to imply a hierarchy of value (as in "good" or "bad"), but rather are seen in terms of yin-yan in the Tai Chi Diagram. These two words reflect the Chinese worldview, across schools of philosophies, of the importance of understanding the world holistically. Both "positive' and 'negative", yin and yan, are seen as one. This One is the Tao and there is a constant flow between one and the other, in an ever-changing world.

"weakness is the means the Tao utilizes."

Laozi's use of the word "weakness" can, like his use of the words "positive" and "negative" be misunderstood in the West. In the context of Taoism and this poem, Laozi's refers to "weakness" with no value judgment but understands this to be part of the natural Tao, the natural flow of things. He notes that we all move between weak and strong at different times. This means that the strong will one day become weak and vise versa (Zhou, Cheng \& Lui, 2019).

"All creation is born from the being, while being is born from the non-being."

Laozi explains that the non-being is the Tao that cannot be described. It is, he tacitly informs us, the wordless, inferred information in our lives. He points out that we make sense of our experience of the moment-to-moment shift between being and non-being (Zhou, Cheng \& Lui, 2019).

Lao Zi's description therefore enables us to open to the others while in both the "negative" or "positive" condition, to understand that everything changes, that what may appear one way at one moment, can change the very next, and that for the most 
part what we see is born from that which we are not yet completely aware of and is most probably still indefinable. Perhaps it is sufficient to walk with the Tao, graciously wandering $(y u)$ in these cyclical moments of negative and positive, yin and yan. When we read the words of the authors, we may agree or disagree, sometimes we are on opposite sides, we may take a firm standpoint or utilize the means of weakness, we may open to the other and (re)think. We acknowledge the voices of these contributions that reflect both our wisdom and our limitations.

\section{Responses to the articles in the spirit of Taoist philosophy}

Rainbow Ho's article looks at the notion of independent in an interdependent culture. She ponders over the tension between the two - the push to independence in an interdependent culture, an Asian global city. Bianca Lee explores the reality of working in Hong Kong and how she had adapted her practice to form what she calls home-based art therapy.

It is possible to perceive a common thread between these two articles. Lee's article gives an example of the way in which the dynamic of independence and interdependent culture looks in the local context. We may ask: how has the inter-play between independence and interdependence made home-based art therapy applicable to the local context?

Could this be connected to the broader narrative of China? According to Mok (2014), the idea of "China" is an ambiguous one. It is always in flux in response to the national border, and the ancient and modern worldview of "China." To a great extent, the idea of "China" is always in a process of renewing its identity through its interactions with its neighboring countries (independence and interdependence). This is applicable to the idea of "Hong Kong." Could it be that one of the ways to live in a place in which there is a tension between the push to be independent and the pull to be an interdependent culture, could be wander $(y u)$ ?

Although the following story tells us the relationship of man to nature, it could also be applied to human relationships and the idea of $y u$. In the book, Carefree Wandering in Vastness, Zhuangzi tells a story about "no self" with the Taoist characters Song Rongzi and Liezi. According to his words, Song Rongzi is a grounded person who despises vanity by discerning between glory and shame. Yet, he has weaknesses. Liezi rides the wind deftly for fifteen days before returning to the earth. He practices $y u$ among the heavens and earth instead of seeking his fortune. Yet, he still needs to depend on the help of the wind. Therefore, Zhuangzi said,

If a man can live in harmony with the laws of nature, master the change of the six energies (yin, yang, wind, rain, dimness, and brightness) and wander through the realm of infinity, then what is there for him to wait for? Therefore, it is said that the perfect man has no self; the godly man has no merit; the sage has no fame.

(trans. Zhou, Cheng \& Lui 2019, p. 267)

The perfect man is at ease and grounded in where he is able to go beyond the "dependent." He does not depend on any external conditions. Thus, the perfect man, who is in unity 
with the universe, is "independent" (p. 269). Ironically, this independency has nothing to do with self-centeredness. Instead, the perfect man plays along with the naturalness of the tens of thousands of places in the world. As in the words of Zhuangzi in the story, the perfect man is the one who can "enjoy the gains that come at the right time and accept all the losses that come naturally." He is living through the interdependency of all relationships with people and things. You are a "perfect man with no-self" when you respond to the vicissitudes of life by staying serene and fearless (p. 271). The freedom of humankind proposed by Zhuangzi is in the nature of being dependent or interdependent? Maybe, he has offered a third way: independent in terms of concepts and behaviors of the egoistical self; while being interdependent by embracing the multitudes in the world.

Aleck Kwon Man Kit looks at the use of the expressive therapies model and how this helps us to integrate multiple identities of being Chinese, gay and HIV positive.

"Tao is the context and ground for Spiritual journeying. Through the process, Tao unifies and harmonizes any and all differences. Besides, Tao lets paradoxical unities be without proliferating dualities" (Vespe, 2017, p. 231). Could this shed light on the existential journey for the "Chinese/gay/HIV positive" person when they are struggling with isolation, death, freedom, and meaninglessness? Particularly, when these themes are interrelated to the person's multiple identities?

"Expressive arts therapy is based upon an aesthetic approach to therapy. It places the arts at the center of its theory and practice. This distinguishes it from more psychologically-oriented approaches" (Levine, 1995, p. 3). As far as I could imagine, a center, can be "the center" while at the same time also be the point of intersection. How could arts (as at the center of Expressive Arts therapy) help similar populations "travel" at the intersections? Do we integrate? Or, do we simply stay or sometimes wander $(y u)$ when we could be able to expand to play with multiple identities?

Esther Yau Ching Nam looks at Chinese calligraphy and its relevance to working with teenagers in a school and group setting. Joanna To explores the connection between Metta meditation (loving kindness meditation), Chinese Buddhism, Chinese calligraphy, and the application to Expressive Arts therapy.

Both these authors have chosen to work with Chinese calligraphy. Joanna has also introduced Buddhist philosophy and the practice of loving-kindness meditation into her art form. It is not always easy to describe Chinese philosophy to non-Chinese people, due to the Chinese mystical way of expression (Fung, 1976). For example, commenting on the writings of Zhuangzi, he said we are "who have-no knowledge but not who have no-knowledge" (Fung, 1976, p. 117). I would draw a parallel between Chinese philosophy and the Chinese art form of calligraphy that definitely has a distinct philosophy and aesthetic. It is not always easy to describe the different aspects of this art form. On one level there is a need for great skill and practice, to perfect the characters, while on another level, the calligraphers need to let go and collaborate with the Chinese notion of $c h^{\prime} i$. This can be described and felt as creative energy (McNiff, 2016) in the process of the making art. In addition, the artwork manifests the $c h$ ' $i$ when its energy affects us (Levine, 2015). 
In terms of applying the art form to different settings and populations, both authors have shown us the breadth of the therapeutic values of Chinese calligraphy either on its own terms or by integrating with other practices such as loving-kindness mediation. A question we may ask however is, in addition to the Expressive Therapies Continuum (ETC) framework that has been used by both authors, what aspects of Western thinking could make sense of the need to control, while at the same time, the need to let go?

Leung Wai $\mathrm{Yu}$ engages traditional Chinese landscape, Zen Buddhism, and Taoist ideas in her understanding of herself as well as in her practice as an Expressive Arts therapist.

Among psychological commentaries, one of the rare interpreters of the text of Zhuangzi is Vespe (2017). Vespe speaks of the relationship of human and Tao in terms of our relationship to heaven-earth. He continues, "Heaven-Earth is synonymous with Nature and is the connecting, joining and integrating of the celestial and terrestrial dimensions of reality, of the sky and the soul" and "The human being is the connecting link that joins heaven and earth" (Vespe, p. 216). The discussion of wu-wei in the Taoist tradition by the author in connection to her Chinese landscape paintings seems to mirror these words. These paintings serve as the negative (seemingly absent) of the positive (presence) as the human figure is usually absent from or disappears into the landscape. As usual, the concreteness of the people, and the hills at times, are depicted through the negative space of the images. Through practicing $w u$-wei, the Chinese painters have preserved and to an extent sublimated both the naturalness of nature and the people in the paintings.

The author also addresses address the therapeutic effect of Chinese landscape paintings for both herself and for her clients. This idea inspired me to consider the relationship between $w u$-wei and art making that applies for both therapist and the client. The Chinese character, 遊 $(y u)$ relates to travel and game. It makes sense therefore, to apply the notion of wander $(y u)$ to the ideas of freedom and play. The exact environment the Expressive Arts therapists facilitates; is the safe place in which to play. In order to arrive at such a state, the person must do $w u$-wei which is effortless activities requiring "letting go of striving after a goal" and "paying close attention to what is happening" (Levine, 2015, p. 21). In the words of Expressive Arts therapist Levine, wu-wei is "a way of becoming present, of returning to what is called in Taoism the 'Uncarved Block' (pu)" (p. 21). Then, in such a simple state of being like an infant (i.e. the major metaphor used by Zhuangzi for $p u$ ), the two people connect. Yet, they also connect through the act of making art in the Expressive Arts therapy (EXA) studio in the spirit of wu-wei. In fact, the discipline of EXA could be taken as "'art-in-relationship' - decentering in the presence of the other who can 'hold' the client as they enter into the transitional space of creative action" (Levine, 2019, p. 49).

Gracelynn Chung Yan-Lau takes the courageous healing journey to decolonize herself and her scholarship, i.e., her personal and professional self, through her experimental method of a body memories map.

In light of the ontological and epistemological foundations and methods concerning the indigenous culture, coupled with the aforementioned idea of "China/Chinese," I have 
begun to (re)search for the "indigenous" elements in the discipline of Expressive Arts therapy. What are the core elements (indigenous in this profession) in the philosophy, therapy, method, and practice of Expressive Arts therapy? In the words of Taoist sage, it would be, "How to preserve the 'naturalness' of the phenomenon?"

Maybe the author's intention to stay with the "borderlands" "in-between" and "no knowing" is an appropriate strategy for the task. In this manner, one suspends the preconceptions of being an artist/researcher/teacher in A/r/tography. As Zhuangzi said, "If everyone considers their preconceptions as teachers, then who does not have a teacher? Why does one have to search for the rule of change? ... Why can't they perceive the world without preconceptions?" (Zhuangzi, "Equalizing Matters Discourse")

Sara Y. Chu illustrates how, she in her own particular way, makes meaning of the model she has learned and gains insight on a personal and professional level.

At the beginning of the article, the author puts forward her contemplation of (re)thinking. In terms of the practicalities deeply connected to the nature of Chinese philosophy (that is mostly written for actions in times of instability during times of war), could we reframe the meaning of epistemology as not only the search for linear knowledge based on logic but as knowledge gained by the way (tao), a knowledge based on the lived experience, that will lead to a better living world, for example, awareness of one's compassion as a virtue (te) in action?

If the answer to the question could be yet another question (as suggested in the author's conclusion of the article), then would the use of arts by the Expressive Arts therapists be a distinct manner of inquiry leading us not to the solution but to the meaningful question(s)? Would asking an appropriate question be a kind of virtue (te) for the people involved in it?

These articles have shown us the multi-faceted happenings of Expressive Arts therapy in Hong Kong. The authors never meant to impose a single solution when applying the profession of Expressive Arts therapy in the local contexts. Cultural pride, interestingly, exists among us within a culture. Being aware of this, I could only comment from the perspective of what I know (i.e., Taoist philosophy) in my inadequate response to these articles in the Special Hong Kong Section. I believe both the East and the West would agree that Zhuangzi made a significant contribution to the epistemology of humankind. There is a story in the "dissertation" of Zhuangzi in which the protagonist Knowledge wandered north looking for Tao (Zhuangzi, chapter 22). She met different teachers and finally encountered $T i$ who wu-wei (I am using the word here as a verb) her to exercise no-thought and follow no-way. Tao, as epistemology and also as ontology, is generative as creatively making meanings only if we stay away from being Tao, i.e., assuming one has possessed the answer or truth. Both East and West are on our ways to knowing Expressive Arts therapy.

\section{About the Author}

Ka Kit (KK) Lai, PhD candidate, REAT, RCAT registered Expressive Arts therapist and registered art therapist is the founding Director of the Kunst Expressive Arts Therapy Academy in Hong Kong. Kunst is a member of The International Network of Expressive Arts Therapy Training Centers that interconnects institutes in North 
America, Latin America, Europe, and Asia. KK is currently a faculty member of the European Graduate School where he teaches and supervises students of the Master's programs in Expressive Arts therapy.

\section{References}

Fung, Y.-L. (1976). A Short History of Chinese Philosophy: A Systematic Account of Chinese Thought from Its Origins To The Present Day. New York: The Free Press.

Levine, S. K. (1995). From chaos to poiesis: Reflections on Expressive Arts therapy. IEATA International Expressive Arts Therapy Association Newsletter, 1(1).

Levine, S. K. (2015). The Tao of poiesis: Expressive Arts therapy and Taoist

philosophy. Creative Arts in Education and Therapy - Eastern and Western Perspectives, 1(1): 15-25.

Levine, S. K. (2019). Philosophy of Expressive Arts Therapy: Poiesis and the Therapeutic Imagination. London: Jessica Kingsley Publishers.

Mok, 莫兆光 (2014). What is China? Territory, nation, culture and history 何為中國? 疆域、民族、文化與歷史. Hong Kong: Oxford University Press (China).

McNiff, S. (2015). A China focus on the arts and human understanding. Creative Arts in Education and Therapy - Eastern and Western Perspectives, 1(1): 6-14.

McNiff, S. (2016). Ch'i and artistic expression: An East Asian worldview that fits the creative process everywhere. Creative Arts in Education and Therapy - Eastern and Western Perspectives, 2(2): 12-20.

Vespe, R. B. (2017). Chuang Tzu's NeiP'ien Psychotherapeutic Commentaries: A Wayfaring Counselor's Rendering of the Seven Interior Records. Regent Pr.

Zhou, W., Cheng, T., \& Lui, T. (2019). Laozi and Zhuangzi: A Modern Translation and Contemporary Interpretation. Hong Kong: Yew Chung Publishing House. 